\title{
AC 2011-279: EDGE DETECTORS IN IMAGE PROCESSING
}

\section{John Schmeelk, Virginia Commonwealth University/Qatar}

Dr. John Schmeelk is a Professor of mathematics at Virginia Commonwealth University teaching mathematics at VCU/Qatar campus in Doha, Qatar. He received his PhD from George Washington University in Washington, D.C. He has been an invited speaker to conferences in Australia, Brazil, Bulgaria, Canada, China, Hungary, India, United Arab emmirate, Qatar and many other lands. 


\title{
Edge Detectors in Image Processing
}

\begin{abstract}
Image edge detection is an integral component of image processing to enhance the clarity of edges and the type of edges. Issues regarding edge techniques were introduced in my 2008 paper on Transforms, Filters and Edge Detectors. ${ }^{15}$ The current paper provides a deeper analysis regarding image edge detection using matrices; partial derivatives; convolutions; and the software MATLAB 7.9.0 and the MATLAB Image Processing Toolbox 6.4. Edge detection has applications in all areas of research, including medical research ${ }^{6,16}$. For example, a patient can be diagnosed with an aneurysm by studying the shape of the edges in an angiogram. An angiogram is the visual view of the blood vessels (see Figure 1-Vascular Web image). The previous paper $^{15}$ studied selected letters using vertical, horizontal, and Sobel transforms. This paper will study images to include the letter $O$ and two images, Cameraman and Rice that are included in the Image Processing Toolbox 6.4. We then compare the techniques implemented in the previous paper ${ }^{15}$ and the images, letter $O$ and those of Cameraman and Rice, using vertical, horizontal, Sobel, and Canny transforms implementing the software MATLAB 7.9.0 and the Image Processing Toolbox 6.4.
\end{abstract}

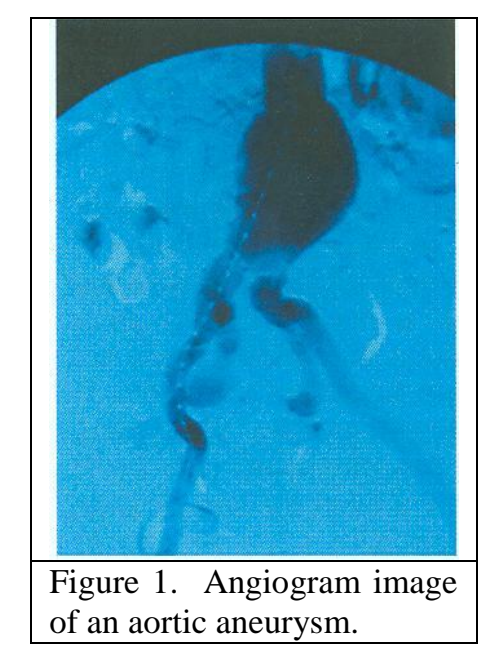

\section{Introduction}

To help motivate this paper, we provide an introduction to the edger problem in image processing by implementing matrix techniques, partial derivatives and convolutions. Section (II) provides an introduction to matrix and partial derivatives and how they are applied to the pixels to obtain the gray level value in black and white images. Section (III) introduces the mathematical requirements for a few specific examples, such as the vertical, horizontal, and Sobel Edge Detectors. Section (IV) provides the reader with a 
series of illustrations that demonstrate edging techniques in a three-dimensional image, and images directly taken from a camera. We compare results by developing mathematical procedures, including convolutions using MATLAB 7.9.0 versus using the Image Processing Toolbox 6.4.

\section{Some Notions and Notations}

Resolution of an image improves as the number of pixels increase. A current laptop in advertisements displays an image using 1680x1050 pixels. The number of pixels continues to increase every day as technology progresses. Each pixel location designated by the coordinates, $\left(\mathrm{x}_{\mathrm{i}}, \mathrm{y}_{\mathrm{j}}\right)$ contains a gray level value indicating the shade of gray within the image at that point. The values are on a scale of 0 to 255 , whereby 0 corresponds to white and 255 corresponds to black. The value of the gray level, at this pixel lattice point, $\left(\mathrm{x}_{\mathrm{i}}, \mathrm{y}_{\mathrm{j}}\right)$ is designated by $\mathrm{f}\left(\mathrm{x}_{\mathrm{i}}, \mathrm{y}_{\mathrm{j}}\right)$. Before we continue with the edge detection analysis, we briefly review a few matrix and calculus techniques to familiarize the reader with the mathematical techniques implemented in this paper. We first recall the familiar dot product for two vectors, $\mathbf{x}, \mathbf{y}$, to be $\mathbf{x} \bullet \mathbf{y}=\sum_{i=1}^{2} x_{i} y_{i}$. From this dot or inner product we define the norm to be $\|x\|^{2}=\sum_{i=1}^{2} x_{i} y_{i}$. Then we obtain the familiar and very important result to many applications: the cosine of the angle between the two vectors, $\mathbf{x}$ and $\mathbf{y}$, satisfies the equation, $\cos (\theta)=x y /(\|x\| \mid y \|)$. We know the maximum value for the cosine occurs when the two vectors coincide, giving a value, cosine $(0)=1$. This is an important observation in edge detection and will later be explained. We now evaluate the values of the grey levels between neighboring pixel locations. This will be determined by introducing the partial derivative formulas,

$$
\frac{\partial f(x, y)}{\partial x}=\lim _{\Delta x \rightarrow 0} \frac{f(x+\Delta x, y)-f(x, y)}{\Delta x}
$$

and

$$
\frac{\partial f(x, y)}{\partial y}=\lim _{\Delta y \rightarrow 0} \frac{f(x, y+\Delta y)-f(x, y)}{\Delta y} .
$$

The distance between pixel locations will be normalized to be 1 so all of the increments in the partial derivative formulae will be equal to one. This then gives,

$$
\frac{\partial f(x, y)}{\partial x} \approx \frac{f(x+1, y)-f(x, y)}{1}
$$

and 


$$
\frac{\partial f(x, y)}{\partial y} \approx \frac{f(x, y+1)-f(x, y)}{1} .
$$

We now denote the function, $f(x, y)$, to be the gray level values between neighboring pixels in the horizontal and vertical directions, respectively giving us the formulas, $\mathrm{f}\left(\mathrm{x}_{\mathrm{i}+1}, \mathrm{y}_{\mathrm{j}}\right)-\mathrm{f}\left(\mathrm{x}_{\mathrm{i}}, \mathrm{y}_{\mathrm{j}}\right)$ and $\mathrm{f}\left(\mathrm{x}_{\mathrm{i}}, \mathrm{y}_{\mathrm{j}+1}\right)-\mathrm{f}\left(\mathrm{x}_{\mathrm{i}}, \mathrm{y}_{\mathrm{j}}\right)$. The spatial locations, $\mathrm{x}_{\mathrm{i}}$ and $\mathrm{y}_{\mathrm{j}}$, can only take on integer values given by their integer locations.

\section{Convolution and Edge Detectors}

To compute the adjacent differences between neighboring pixel locations, we introduce the usual calculus definition for convolution given by the formula,

$$
h(x, y) * f(x, y)=\int_{-\infty-\infty}^{+\infty+\infty} \int_{-\infty} h\left(k_{1}, k_{2}\right) f\left(x-k_{1}, y-k_{2}\right) d k_{1} d k_{2},
$$

and its discrete version by the formula,

$$
h\left(n_{1}, n_{2}\right) * f\left(n_{1}, n_{2}\right)=\sum_{k_{1}=-\infty}^{\infty} \sum_{k_{2}=-\infty}^{\infty} h\left(k_{1}, k_{2}\right) f\left(n_{1}-k_{1}, n_{2}-k_{2}\right) .
$$

Research efforts reported that we can reduce the discrete convolution to be a special three by three matrix, which will play the role of a convolute and select our function, $h\left(\mathrm{n}_{1}, \mathrm{n}_{2}\right)$, to have the matrix values,

$$
\mathbf{h}=\left(\begin{array}{ccc}
h(-1,1) & h(0,1) & h(1,1) \\
h(-1,0) & h(0,0) & h(1,0) \\
h(-1,-1) & h(0,-1) & h(1,-1)
\end{array}\right)=\left(\begin{array}{ccc}
-1 & 0 & 1 \\
-1 & 0 & 1 \\
-1 & 0 & 1
\end{array}\right)
$$

The arguments $\left(\mathrm{n}_{1}, \mathrm{n}_{2}\right)$ in $\mathrm{h}\left(\mathrm{n}_{1}, \mathrm{n}_{2}\right)$ of the first array are easily remembered by noting that they are the needed lattice point coordinates referred to as a Cartesian coordinate system. This is illustrated in Figure 2. Clearly, the reduced array for $h\left(n_{1}, n_{2}\right)$ is part of the complete array, where $\mathrm{h}\left(\mathrm{n}_{1}, \mathrm{n}_{2}\right)$ is equal to zero whenever $\left|n_{1}\right|$ or $\left|n_{2}\right|>2$. Next, we convolve the function, $h\left(\mathrm{n}_{1}, \mathrm{n}_{2}\right)$, with the function, $\mathrm{f}\left(\mathrm{n}_{1}, \mathrm{n}_{2}\right)$, and obtain

$$
\begin{gathered}
h\left(n_{1}, n_{2}\right) * f\left(n_{1}, n_{2}\right)=\sum_{k_{1}=-1}^{1} \sum_{k_{2}=-1}^{1} h\left(k_{1}, k_{2}\right) f\left(n_{1}-k_{1}, n_{2}-k_{2}\right) \\
=\mathrm{f}\left(\mathrm{n}_{2}-1, \mathrm{n}_{2}+1\right)-\mathrm{f}\left(\mathrm{n}_{1}+1, \mathrm{n}_{2}+1\right)+\mathrm{f}\left(\mathrm{n}_{1}-1, \mathrm{n}_{2}\right)-\mathrm{f}\left(\mathrm{n}_{1}+1, \mathrm{n}_{2}+1\right)+\mathrm{f}\left(\mathrm{n}_{1}-1, \mathrm{n}_{2}+1\right)-\mathrm{f}\left(\mathrm{n}_{1}+1, \mathrm{n}_{2}-1\right) .
\end{gathered}
$$


Investigating this last result reveals that it gives the difference of three columns of pixel values in the horizontal direction. If we check the literature ${ }^{8,9}$, we find that this is the approximation used in the horizontal direction in several leading software imageprocessing packages. The function, $\mathrm{h}\left(\mathrm{n}_{1}, \mathrm{n}_{2}\right)$, is called the kernel of the convolution, and when we change its values, we obtain different edgers. The edge is the portion of the image where there is a sudden change in gray levels. The edger implemented selects a particular feature in the image, which is beneficial to the particular application. The kernel for vertical edging is given by

$$
\mathbf{h}=\left(\begin{array}{rrr}
1 & 1 & 1 \\
0 & 0 & 0 \\
-1 & -1 & -1
\end{array}\right) .
$$

A more sophisticated edger is the Sobel Edger, which uses the gradient to approximate the edges. Since the gradient includes both horizontal and vertical components, two kernels are employed, given by the matrices,

$$
\left(\begin{array}{lll}
-1 & 0 & 1 \\
-2 & 0 & 2 \\
-1 & 0 & 1
\end{array}\right),\left(\begin{array}{ccc}
1 & 2 & 1 \\
0 & 0 & 0 \\
-1 & -2 & -1
\end{array}\right)
$$

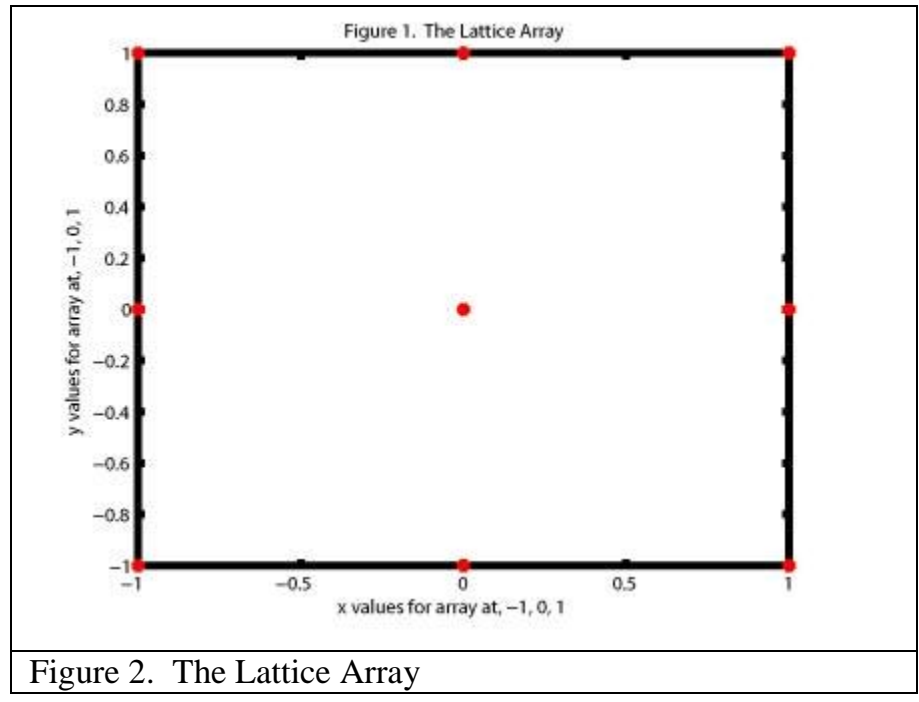

\section{Illustrations using Edge Detectors}

Figures 3-6 show the completed letter, $O$, using mathematical techniques briefly included in Section II and convolutions briefly described in Section III. Figures 3-6 
employ mathematics using MATLAB 7.9.0 and NOT the Toolbox Software 6.4. Figure 3 illustrates the letter $O$. We then employ a vertical edge detector on the letter $O$ shown in Figure 4. Again a horizontal edge detector and Sobel Transform are applied on the letter $O$ and illustrated in Figures 5 and 6, respectively.
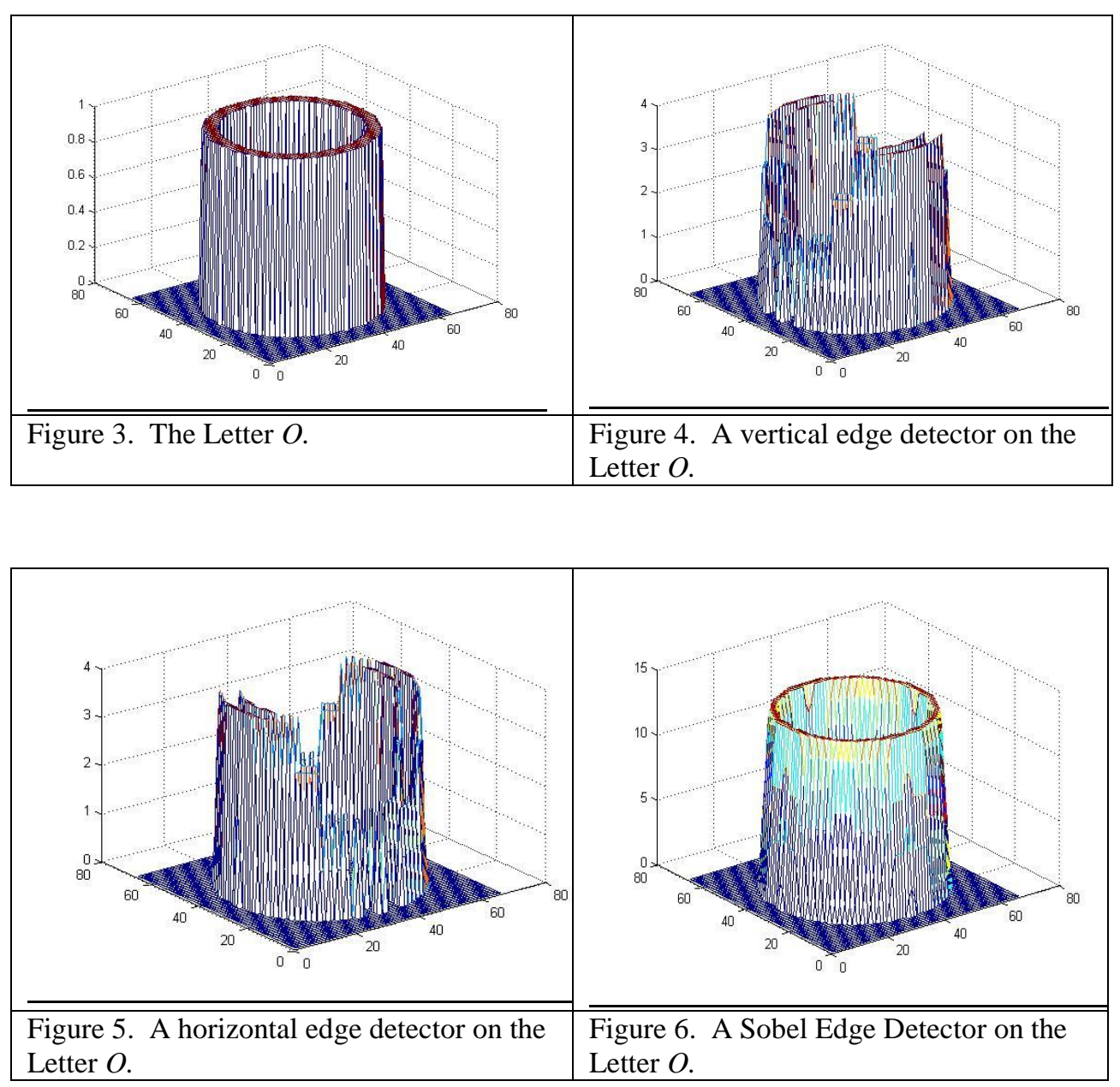

We now use the Image Processing Toolbox Version 6.4 to compare the edge detection for the given images. The toolkit requires a single matrix whereby one must convert a JPEG format file to a gray-scale format file. The MATLAB 7.7.0 command for this is as follows:

$$
\mathrm{J}=\operatorname{rgb} 2 \operatorname{gray}(\mathrm{I}) \text {, }
$$

where $I$ is the image file in JPEG format and $J$ is the file converted to gray-scale format. We select the image, Letter $O$.tif illustrated in Figure 3, convert it to the gray-scale format, and apply the Sobel Edge Detector to it as illustrated in Figure 7. We compare the difference for the Sobel Transform on the Letter $O$ (illustrated in Figure 6) and the 
Matlab Toolbox using the Sobel Edge Detector (see Figure 7). We also compare the Canny Edge Detector illustrated in Figure 8 to that of Figure 6.

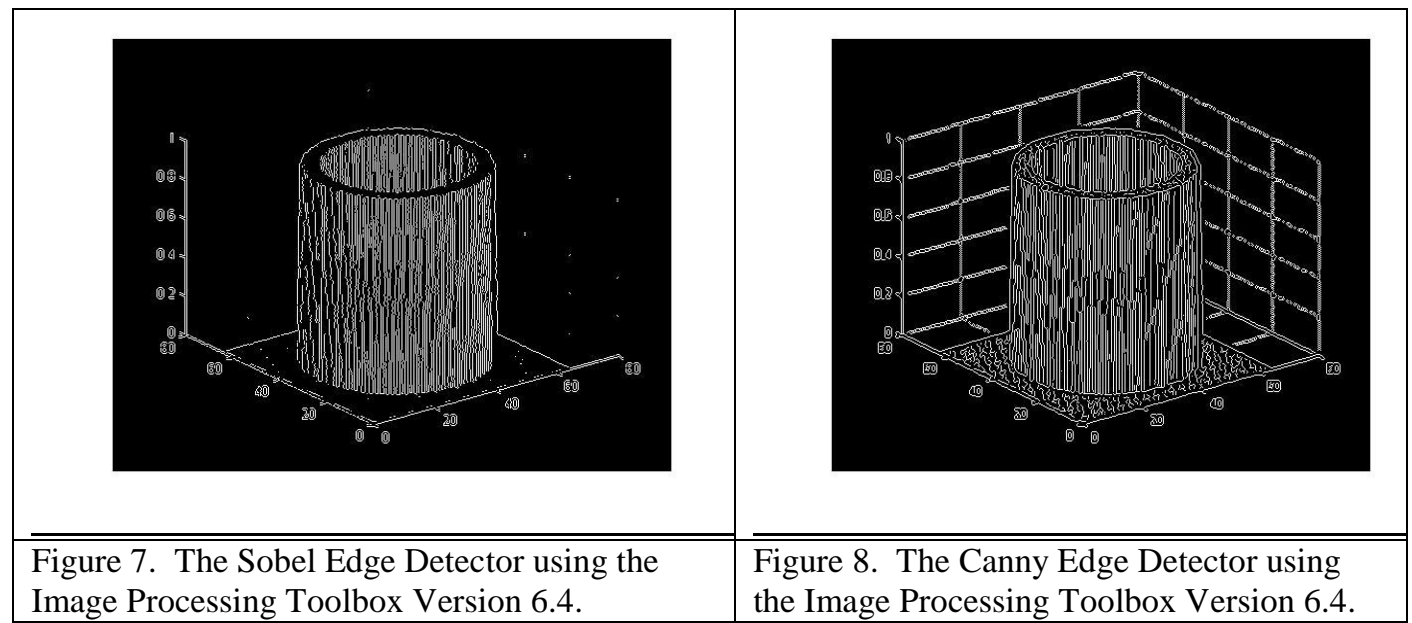

We import the black and white example image, cameraman.tif included in the MATLAB Imaging Process Toolkit (see Figure 9) to extract the edges of the image. We apply the mathematical development for the Sobel Edge Detector by implementing the software MATLAB 7.7.0 and illustrate the result in Figures 12 We can see a stronger edge detection in Figures 12 as compared to the MATLAB Imaging Process Toolkit implementing the Sobel and Canny Edge Detectors illustrated in Figures 10 and 11.

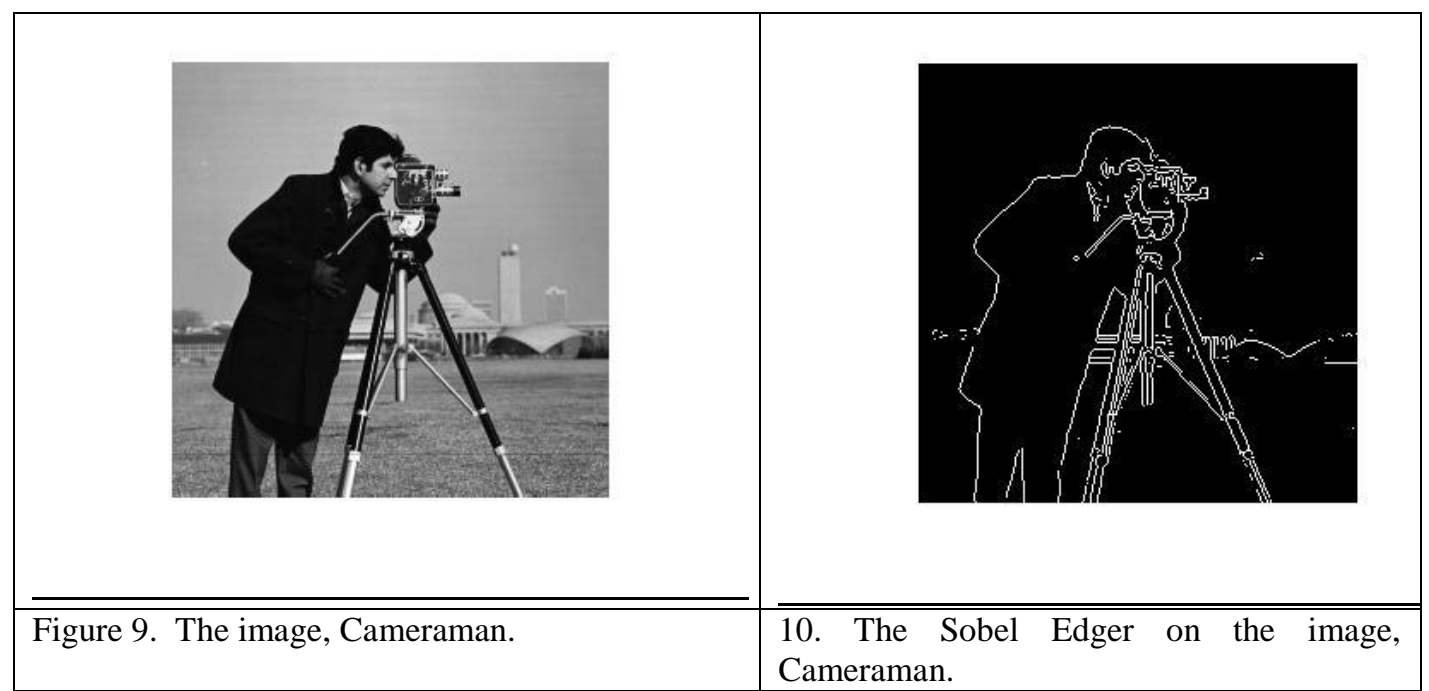




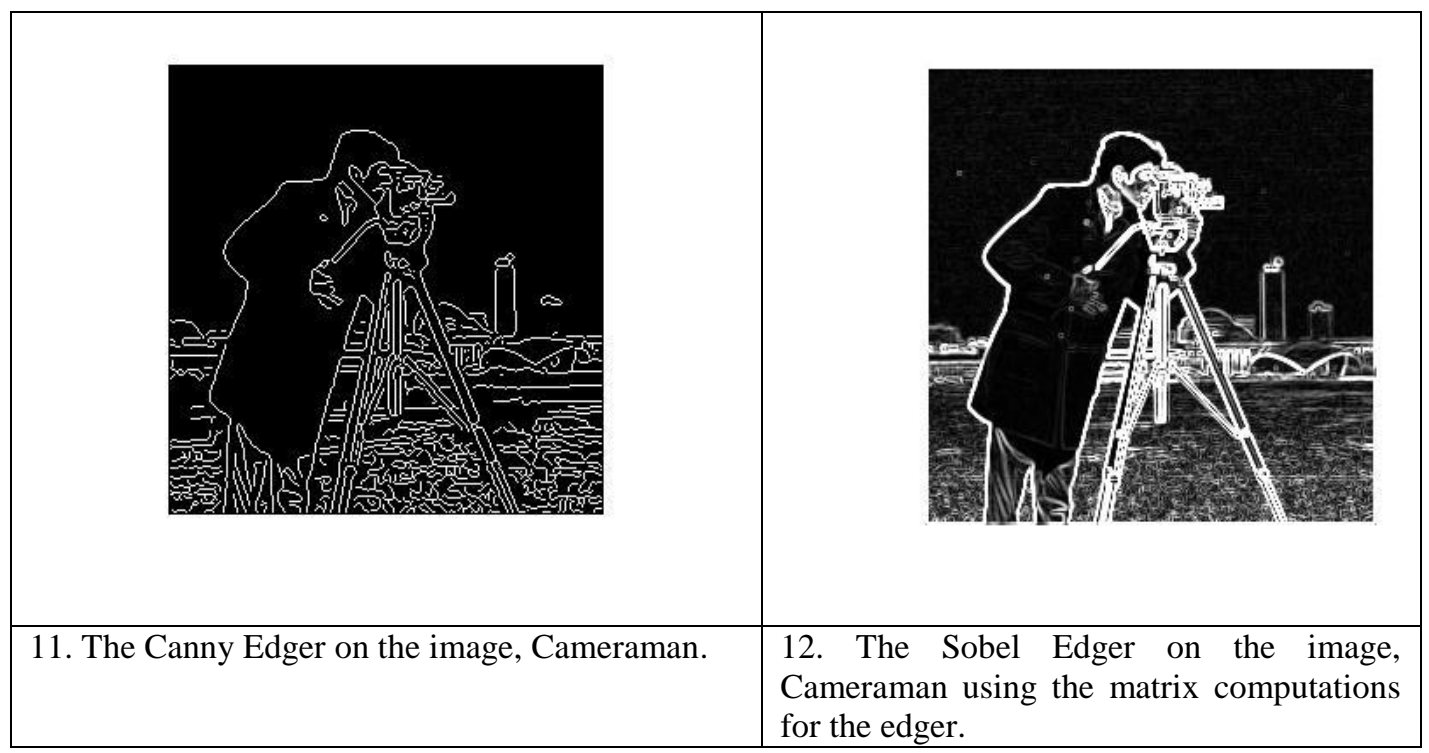

Furthermore we import the black and white image, Rice.png (Figure 13) contained in the MATLAB Image Processing Toolkit. We then consider the image, Rice.png, and apply the Sobel and Canny Edger in the MATLAB Image Processing Toolkit and again compute the Sobel Edger and illustrate the mathematical computations shown for it. They are included in Figures 14-17, respectively. Again, the results are similar to the image cameraman.tif.

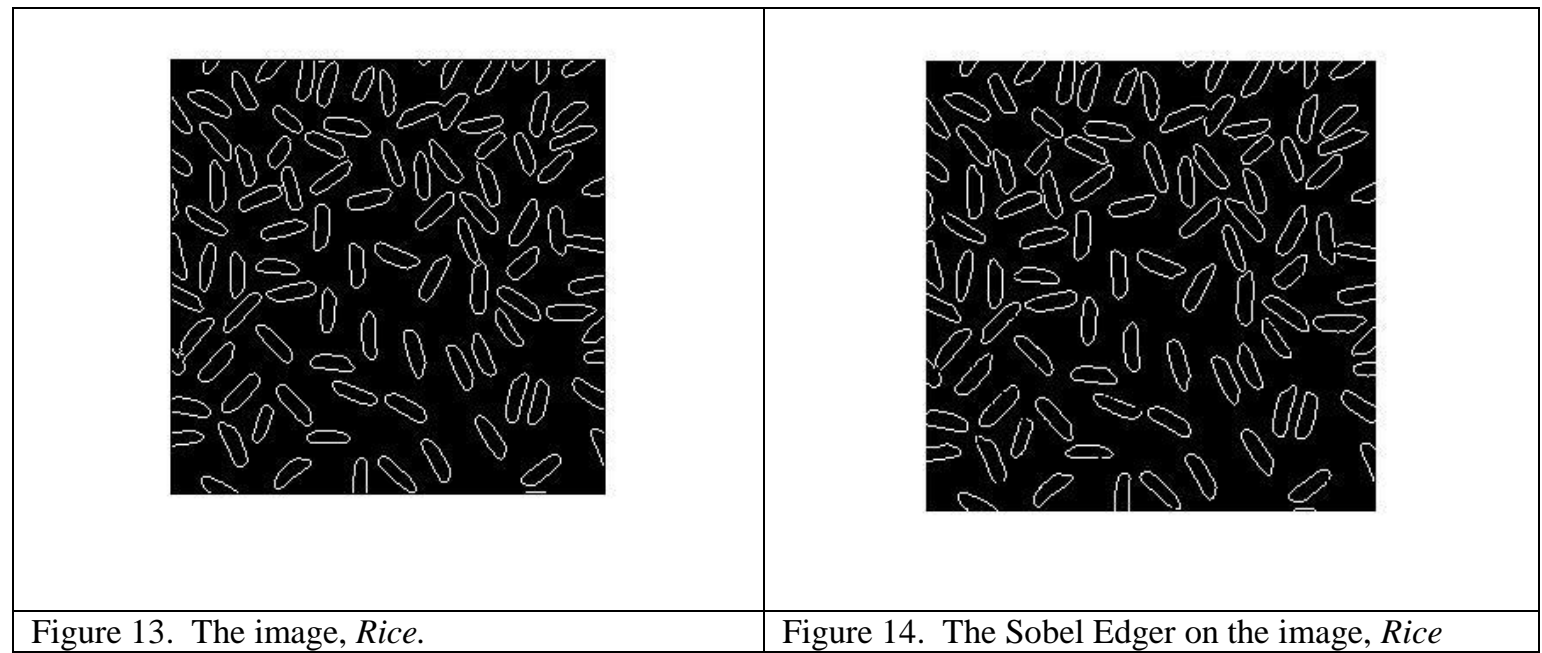




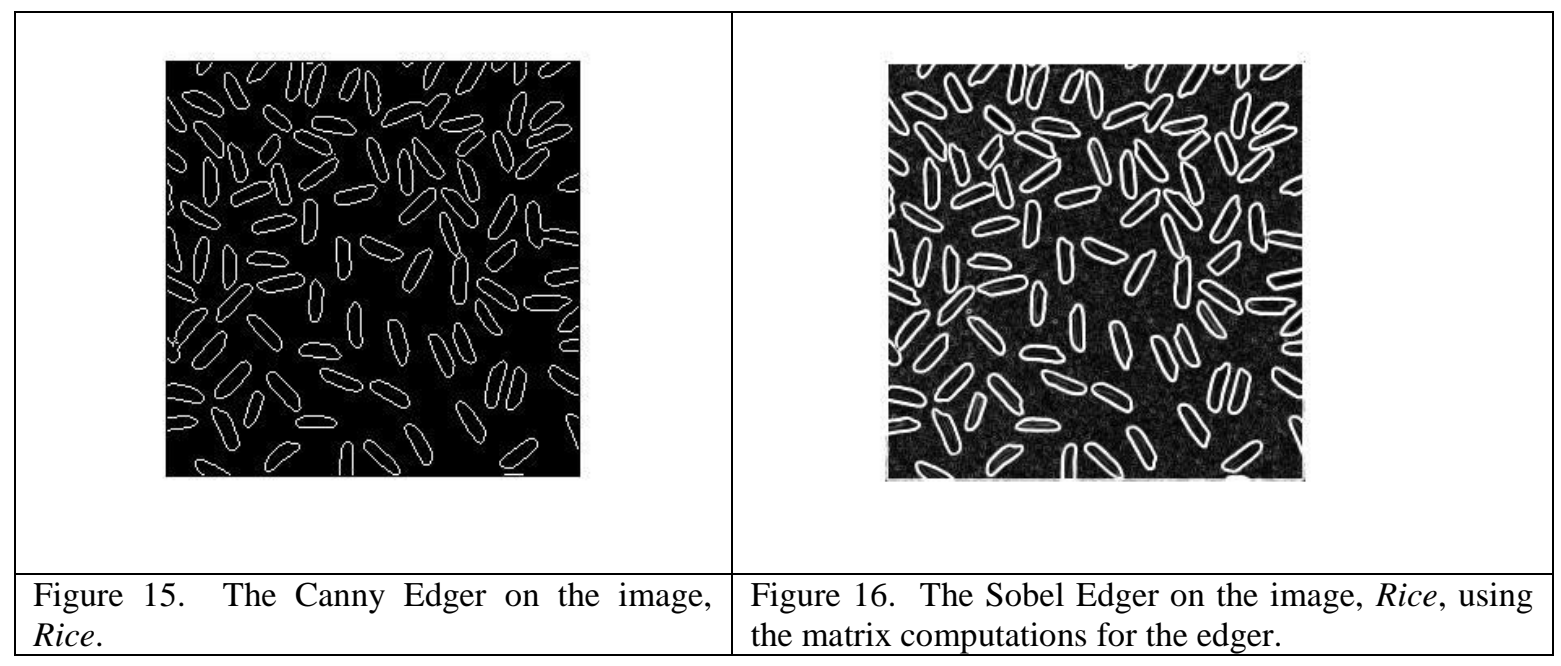

\section{Conclusion}

As seen by the previous images, the mathematical development techniques briefly discussed in Sections III and IV illustrate strong edges. Appendix A summarizes the relative effectiveness of different edging techniques. The Image Toolkit without any further enhancement techniques included, somewhat submerges the clarity of the edges. However, the particular application being used by the researcher must review both techniques to identify the appropriate desired results for the required goal. 
Bibliography

1. Andrews, H.C. \& Hunt, B.R., Digital Image Restoration, Prentice Hall, N.J., (1977).

2. Ballard, D.H., "Parameter Nets", Artificial Intelligence, 22, (1984), 235-267.

3. Ballard, D. H. \& Brown, C.M., Computer Vision, Prentice Hall, N.J., (1982).

4. Batchelor, B.G., Pattern Recognition, Plenum Press, N.Y., (1978).

5. Campbell, F.W., \& Robson, J.G., "Application of Fourier Analysis to the Visibility of Gratings", J. Physiol. 197, (1968), 551-566.

6. Demirkaya, O., Asyali, M., H., Sahoo, P.K., Image Processing with MATLAB-Applications in Medicine and Biology, CRC Press, Florida, (2009).

7. Gonzalez, R.C., \& Wintz, P., Digital Image Processing, Addison-Wesley Publ. Co., MA. (1987).

8. Jain, A., K., Fundamentals of Digital Image Processing, Prentice Hall, NJ, (1989)

9. Lim, J., S., Two-Dimensional Signal and Image Processing, Prentice Hall, NJ, (1990).

10. Nagy, G., "State of the Art in Pattern Recognition", Proc. IEEE, 56, (1968), 836-862.

11. Pedrycz, W., "Fuzzy Sets in Pattern Recognition; Methodology and Methods", Pattern Recognition, 20 No. 1-2, (1990), 121-146.

12. Pratt, W., K., Digital Image Processing, John Wiley \& Sons, NY, (1991).

13. Russ, C. J. and Russ, J. C., Introduction to Image Processing and Analysis, CRC Press, Florida, (2008).

14. Schalkoff, R. J., Digital Image Processing and Computer Vision, John Wiley \& Sons, NY, (1989).

15. Schmeelk, J., "Transforms Filters and Edge Detectors in Image Processing", International Journal of Pure and Applied Mathematics, 46, No. 2, (2008), 199-208.

16. Zhang, I., Wang, Q.,G., Qi, J., P.," Processing Technology in Microscopic Images of Cancer Cells in Pleural Fluid Based on Fuzzy Edge Detection Method", Journal of Physics: Conference 2 48, (2006), 329-333.

JOHN SCHMEELK

jschmeelk@qatar.vcu.edu

Virginia Commonwealth University Qatar

Post Office Box 8095

Doha, Qatar

Dr. John Schmeelk is a Professor of Mathematics at Virginia Commonwealth University, where he is engaged in applied mathematical research in distribution theory, image processing and educational pedagogy. He is currently teaching mathematics at the VCU/Qatar campus in Doha, Qatar. He received his PhD from George Washington University in Washington, D.C. He has been an invited speaker to conferences in Australia, Brazil, Bulgaria, Canada, China, Hungary, India, Serbia, the United Arab Emirates, Qatar, and many other lands. 
Appendix A

\section{RELATIVE EFFECTIVENESS OF DIFFERENT \\ EDGING TECHNIQUES}

\begin{tabular}{|c|c|c|c|c|}
\hline Figures & Parameters & Techniques & $\begin{array}{l}\text { Different } \\
\text { views }\end{array}$ & Comments \\
\hline $\begin{array}{c}\text { Figure } 4 \\
\text { vertical } \\
\text { edge } \\
\text { detector } \\
\text { on letter } \\
\quad 0 .\end{array}$ & $\begin{array}{c}\text { vertical } \\
\text { edge } \\
\text { matrix, } \\
\left(\begin{array}{ccc}1 & 2 & 1 \\
0 & 0 & 0 \\
-1 & -2 & -1\end{array}\right)\end{array}$ & $\begin{array}{c}\text { Calculations } \\
\text { using my } \\
\text { Matlab 7.9.0 } \\
\text { program }\end{array}$ & $\begin{array}{c}\text { Different view } \\
\text { of the vertical } \\
\text { edge for } \\
\text { the letter } O\end{array}$ & $\begin{array}{c}\text { This is a three } \\
\text { dimensional } \\
\text { construction using a } \\
\text { Matlab 7.9.0 } \\
\text { platform developing the } \\
\text { letter } O\end{array}$ \\
\hline $\begin{array}{c}\text { Figure } 5 \\
\text { horizontal } \\
\text { edge } \\
\text { detector } \\
\text { on letter } \\
\text { O. }\end{array}$ & $\begin{array}{c}\text { horizontal edge } \\
\text { matrix, } \\
\left(\begin{array}{lll}-1 & 0 & 1 \\
-2 & 0 & 2 \\
-1 & 0 & 1\end{array}\right)\end{array}$ & $\begin{array}{c}\text { Calculations } \\
\text { using my } \\
\text { Matlab 7.9.0 } \\
\text { program }\end{array}$ & $\begin{array}{c}\text { Different view } \\
\text { of the horizontal } \\
\text { edges for } \\
\text { the letter } O\end{array}$ & $\begin{array}{c}\text { This is a three } \\
\text { dimensional } \\
\text { construction using a } \\
\text { Matlab 7.9.0 } \\
\text { platform developing the } \\
\text { Letter } O\end{array}$ \\
\hline $\begin{array}{c}\text { Figure 6 } \\
\text { Sobel } \\
\text { edge } \\
\text { detector } \\
\text { on letter } \\
\text { O. }\end{array}$ & $\begin{array}{c}\text { Uses both vertical } \\
\text { and horizontal edge } \\
\text { matrices, } \\
\left(\begin{array}{ccc}1 & 2 & 1 \\
0 & 0 & 0 \\
-1 & -2 & -1\end{array}\right) \text { and } \\
\left(\begin{array}{ccc}-1 & 0 & 1 \\
-2 & 0 & 2 \\
-1 & 0 & 1\end{array}\right) \text {. }\end{array}$ & $\begin{array}{c}\text { Calculations } \\
\text { using my } \\
\text { Matlab 7.9.0 } \\
\text { program }\end{array}$ & $\begin{array}{c}\text { Different view } \\
\text { of the Sobel } \\
\text { edges for } \\
\text { the letter } O\end{array}$ & $\begin{array}{c}\text { This is a three } \\
\text { dimensional } \\
\text { construction using a } \\
\text { Matlab 7.9.0 } \\
\text { platform developing the } \\
\text { Letter } O\end{array}$ \\
\hline $\begin{array}{c}\text { Figure } 7 \\
\text { Sobel Edge } \\
\text { detector } \\
\text { on letter } O\end{array}$ & & $\begin{array}{c}\text { Using Image } \\
\text { Processing } \\
\text { Toolbox } \\
\text { Version } 6.4\end{array}$ & $\begin{array}{l}\text { Must change the } \\
\text { image to a } \\
\text { gray-scale } \\
\text { format }\end{array}$ & $\begin{array}{c}\text { A little too dark for my } \\
\text { purposes. } \\
\text { I just used the software } \\
\text { without any } \\
\text { enhancements. }\end{array}$ \\
\hline $\begin{array}{c}\text { Figure } 8 \\
\text { Canny Edge } \\
\text { detector on } \\
\text { letter } 0\end{array}$ & & $\begin{array}{l}\text { UsingImage } \\
\text { Processing } \\
\text { Toolbox } \\
\text { Version } 6.4\end{array}$ & $\begin{array}{l}\text { Must change } \\
\text { the image to } \\
\text { a gray-scale } \\
\text { format }\end{array}$ & $\begin{array}{c}\text { A little too dark for my } \\
\text { purposes. } \\
\text { I just used the software } \\
\text { without } \\
\text { any enhancements. } \\
\end{array}$ \\
\hline $\begin{array}{c}\text { Figure 10 } \\
\text { Sobel Edge } \\
\text { detector } \\
\text { on image } \\
\text { Cameraman } \\
\end{array}$ & & $\begin{array}{c}\text { Using Image } \\
\text { Processing } \\
\text { Toolbox } \\
\text { Version } 6.4\end{array}$ & $\begin{array}{c}\text { Cameraman } \\
\text { image is in the } \\
\text { Toolbox library. }\end{array}$ & $\begin{array}{c}\text { A little too dark for my } \\
\text { purposes. } \\
\text { I just used the software } \\
\text { without } \\
\text { any enhancements. } \\
\end{array}$ \\
\hline $\begin{array}{l}\text { Figure 11 } \\
\text { Canny Edge } \\
\text { detector } \\
\text { on image } \\
\text { Cameraman } \\
\end{array}$ & & $\begin{array}{c}\text { Using Image } \\
\text { Processing } \\
\text { Toolbox } \\
\text { Version } 6.4\end{array}$ & $\begin{array}{l}\text { Cameraman } \\
\text { image is in the } \\
\text { Toolbox library }\end{array}$ & $\begin{array}{l}\text { A little too dark for my } \\
\text { purposes. I just used the } \\
\text { software without } \\
\text { any enhancements. }\end{array}$ \\
\hline
\end{tabular}




\begin{tabular}{|c|c|c|c|c|}
\hline $\begin{array}{c}\text { Figure 12 } \\
\text { Sobel Edge } \\
\text { detector } \\
\text { on image } \\
\text { Cameraman }\end{array}$ & $\begin{array}{l}\text { Uses both vertical } \\
\text { and horizontal edge } \\
\text { matrices, } \\
\left(\begin{array}{ccc}1 & 2 & 1 \\
0 & 0 & 0 \\
-1 & -2 & -1\end{array}\right) \text { and } \\
\left(\begin{array}{ccc}-1 & 0 & 1 \\
-2 & 0 & 2 \\
-1 & 0 & 1\end{array}\right)\end{array}$ & $\begin{array}{c}\text { Calculations } \\
\text { using my } \\
\text { Matlab 7.9.0 } \\
\text { program }\end{array}$ & $\begin{array}{l}\text { Use my Matlab } \\
7.9 .0 \text { on the } \\
\text { image } \\
\text { Cameraman. }\end{array}$ & $\begin{array}{l}\text { Sharp and clear for my } \\
\text { purpose. I just used my } \\
\text { matrix calculations } \\
\text { without any } \\
\text { enhancements. }\end{array}$ \\
\hline $\begin{array}{c}\text { Figure } 14 \\
\text { Sobel Edge } \\
\text { detector } \\
\text { on image } \\
\text { Rice }\end{array}$ & & $\begin{array}{c}\text { Using Image } \\
\text { Processing } \\
\text { Toolbox } \\
\text { Version } 6.4\end{array}$ & $\begin{array}{l}\text { Rice image is in } \\
\text { the } \\
\text { Toolbox library. }\end{array}$ & $\begin{array}{l}\text { A little too dark for my } \\
\text { purposes. } \\
\text { I just used the software } \\
\text { without } \\
\text { any enhancements. }\end{array}$ \\
\hline $\begin{array}{c}\text { Figure 15 } \\
\text { Canny Edge } \\
\text { detector } \\
\text { on image } \\
\text { Rice } \\
\end{array}$ & & $\begin{array}{c}\text { Using Image } \\
\text { Processing } \\
\text { Toolbox } \\
\text { Version } 6.4\end{array}$ & $\begin{array}{l}\text { Rice image is in } \\
\text { the } \\
\text { Toolbox library }\end{array}$ & $\begin{array}{l}\text { A little too dark for my } \\
\text { purposes. I just used the } \\
\text { software without } \\
\text { any enhancements. }\end{array}$ \\
\hline $\begin{array}{c}\text { Figure 16 } \\
\text { Sobel Edge } \\
\text { detector } \\
\text { on image } \\
\text { Rice }\end{array}$ & $\begin{array}{l}\text { Same as parameters } \\
\text { in Figure } 12\end{array}$ & $\begin{array}{c}\text { Calculations } \\
\text { using my } \\
\text { Matlab 7.9.0 } \\
\text { program }\end{array}$ & $\begin{array}{l}\text { Use my Matlab } \\
7.9 .0 \text { on the } \\
\text { image Rice. }\end{array}$ & $\begin{array}{l}\text { Sharp and clear for my } \\
\text { purpose. I just used my } \\
\text { matrix calculations } \\
\text { without any } \\
\text { enhancements. }\end{array}$ \\
\hline
\end{tabular}

